\title{
Graphene oxide nanostructures modified multifunctional cotton fabrics
}

\author{
Karthikeyan Krishnamoorthy • Umasuthan Navaneethaiyer • \\ Rajneesh Mohan $\cdot$ Jehee Lee $\cdot$ Sang-Jae Kim
}

Received: 13 July 2011/Accepted: 3 November 2011/Published online: 15 November 2011

(c) The Author(s) 2011. This article is published with open access at Springerlink.com

\begin{abstract}
Surface modification of cotton fabrics using graphene oxide (GO) nanostructures was reported. Scanning electron microscopic (SEM) investigations revealed that the GO nanostructure was coated onto the cotton fabric. The molecular level interaction between the graphene oxide and the cotton fabric is studied in detail using the Fourier transform infra-red (FTIR) spectra. Thermogravimetric analysis (TGA) showed that GO loaded cotton fabrics have enhanced thermal stability compared to the bare cotton fabrics. The photocatalytic activity of the GO-coated cotton fabrics was investigated by measuring the photoreduction of resazurin (RZ) into resorufin (RF) under UV light irradiation. The antibacterial activity was evaluated against both Gram-negative and Gram-positive bacteria and the results indicated that the GO-coated cotton fabrics are more toxic towards the Gram-positive ones. Our results provide a way to develop graphene oxide-based
\end{abstract}

K. Krishnamoorthy $\cdot$ S.-J. Kim

Nanomaterials and System Laboratory, Department of Mechanical System Engineering, Jeju National University, Jeju 690-756, Republic of Korea

U. Navaneethaiyer · J. Lee

Department of Marine Life Sciences, School of Marine Biomedical Sciences, Jeju National University, Jeju Special Self-Governing Province, Jeju 690-756, Republic of Korea

R. Mohan · S.-J. Kim ( $₫)$

Department of Mechatronics Engineering, Jeju National

University, Jeju 690-756, Republic of Korea

e-mail: kimsangj@jejunu.ac.kr

J. Lee

Marine and Environmental Institute, Jeju National University, Jeju Special Self-Governing Province, Jeju 690-814, Republic of Korea devices for the biomedical applications for improving health care.

Keywords Graphene oxide - Antibacterial textiles · Thermogravimetric analysis - Photocatalytic activity . Scanning electron microscope

\section{Introduction}

Textiles can provide suitable substrates for the growth of micro-organisms (Dastjerdi and Montazer 2010). The major problem in health care especially in hospitals is the transmission of bacteria and pathogens from the patients to the workers and viceversa through the textiles used by them. The increasing concern towards health care has been a motivating factor for the production of antimicrobial textiles towards its direct applications in the environment safety and human health care applications (Vigo 1981). Antimicrobial properties into the textiles can be developed by introducing antimicrobial material into the textiles through surface modification process. Several antimicrobial agents which can effectively destroy the microbial growth are available. In these aspects, the use of commercial antimicrobial agents for the modification of textiles has been limited due to their toxicity, need of complex post treatment processes, environmental pollution, and multidrug-resistance (MDR) property of bacteria (French 2005; Sreeprasad et al. 2011). To overcome the MDR effect of bacteria, several researches have been attempted in the recent decades. Nanoparticles (1-100 nm) are increasingly used for biomedical applications due to their ability to sense and detect pathogens (Reddy et al. 2007). The advantage of nanoparticles for antibacterial activity is that it overcomes the MDR of bacteria. Inorganic nanoparticles 
such as $\mathrm{Ag}, \mathrm{Au}, \mathrm{TiO}_{2}, \mathrm{ZnO}$ exhibited antibacterial activity towards several multidrug resistant bacteria (Kumar et al. 2008; Karthikeyan et al. 2009). The applications of nanomaterials in medicine and development of health care products are termed as "nanomedicine" which is a vast growing research for ensuring safety life.

In this scenario, the use of inorganic nanoparticles possessing antibacterial activity for the surface modification of textile becomes a suitable alternative for fabrication of antimicrobial textiles with multifunctional properties (Fu et al. 2005). The nanoparticles such as $\mathrm{Ag}, \mathrm{ZnO}, \mathrm{TiO}_{2}$ have been effectively reinforced to the textiles by several surface modification process such as dip coating, sonochemical method, sol-gel method, chemical reduction method, using polymeric nanocomposites, pad-dry-cure method, sputtering of nanoparticles using plasma polymerization, etc., (Mahltig et al. 2005; Hegemann et al. 2007). The significant advantages of using nanoparticles for the preparation of antimicrobial textiles are not only limited to the antibacterial property, but also significantly improve the thermal stability of the textile fabric, developing photocatalytic property in the textiles which can avoid the growth of organic contaminants in textiles leading to the self-cleaning property (Tsai et al. 2010).

Recently, the antibacterial activity of graphene oxide nanosheets was reported ( $\mathrm{Hu}$ et al. 2010; Akhavan and Ghaderi 2010). Even though graphene has a wide range of applications in semiconductor industry, the biological applications of graphene are limited when compared to graphene oxide. This is because of the chemical structure and properties of GO such as intrinsic luminescence, hydrophilicity, tunable band gap, biocompatibility, and photocatalytic activity which makes them a suitable candidate for biological and biomedical applications (Shukla and Saxena 2011; Joung et al. 2010; Karthikeyan et al. 2011). In this paper, we report the surface modifications of cotton fabrics using GO by a facile method and evaluated their potential antibacterial activity against both Gramnegative and Gram-positive bacteria using modified Hohenstein test. The photocatalytic activity of the GO-coated cotton fabrics is also evaluated by the reduction of Resazurin (RF) into Resorufin (RZ).

\section{Experimental procedure}

Synthesis of graphene oxide nanostructures

GO nanostructures are synthesized according to the modified Hummer's method (Karthikeyan et al. 2011). Briefly, the expandable graphite powders $(2 \mathrm{~g})$ were stirred in $98 \%$ $\mathrm{H}_{2} \mathrm{SO}_{4}(35 \mathrm{ml})$ for $2 \mathrm{~h}$. $\mathrm{KMnO}_{4}(6 \mathrm{~g})$ was gradually added to the above solution while keeping the temperature less than $20^{\circ} \mathrm{C}$. The mixture was then stirred at $35^{\circ} \mathrm{C}$ for $2 \mathrm{~h}$. The resulting solution was diluted by adding $90 \mathrm{~mL}$ of water under vigorous stirring and a dark brown suspension was obtained. The suspension was further treated by adding $30 \% \mathrm{H}_{2} \mathrm{O}_{2}$ solution $(10 \mathrm{~mL})$ and $150 \mathrm{~mL}$ of distilled water. The resulting graphite oxide suspension was washed by repeated centrifugation, first with $5 \% \mathrm{HCl}$ aqueous solution and then with distilled water until the $\mathrm{pH}$ of the solution becomes neutral. The GO nanostructures were obtained by adding $160 \mathrm{~mL}$ of water to the resulting precipitate and sonicated well to attain a uniform suspension of GO.

Surface modification process of cotton fabrics using GO nanostructures

The surface modification of cotton fabrics by GO nanostructures was achieved using a facile approach comprising of dip coating via stirring. Briefly, the cotton fabric $(3 \times 4 \mathrm{~cm}$ dimension) was immersed into the solution containing ( $0.25 \mathrm{~g}$ of GO in water) and allowed to vigorous stirring at $300 \mathrm{rpm}$ for $24 \mathrm{~h}$. After that, the GO-coated fabric was taken from the solution and washed thrice with deionized water for the removal of residual $\mathrm{GO}$ on the surface. The resulting fabric was allowed to dry at $35^{\circ} \mathrm{C}$ for 1 day in a vacuum desiccator. The amount of GO-coated onto the fabric was calculated by weight method by employing the formula given below:

Amount of GO loaded into the fabric $=W_{2}-W_{1}$

where $W_{2}$ is the final weight of GO-coated cotton fabrics, $W_{1}$ is the initial weight of the cotton fabrics.

\section{Characterization techniques}

The UV-vis spectroscopy was performed using Hewlett Packard HP-8453 spectrophotometer. The presence of functional groups in GO, cotton fabrics and GO-coated cotton fabrics was confirmed through the Fourier transform infra-red (FTIR) spectroscopy (Model: Bruker IFS 66/S). The surface morphology of the GO nanostructures and GOcoated cotton fabrics were observed using scanning electron microscope (FE-SEM (JSM-6700F, JEOL Ltd). The thermal properties of the bare cotton fabric and GO-coated cotton fabrics were measured on Perkin Elmer instrument.

Photocatalytic activity of GO-coated cotton fabrics

The photocatalytic activity of GO-coated cotton fabrics was evaluated by measuring the photoreduction of RZ as a function of irradiation time under UV light $(350 \mathrm{~nm})$. RZ is a redox indicator used in various biological assays (Premanathan et al. 2011). It is a phenoxazin-3-one dye, blue in color, having intense absorption at $600 \mathrm{~nm}$ and a 
weak absorption at $380 \mathrm{~nm}$. These bands are assigned to the $\pi-\pi^{*}$ transition of the phenoxazin-3-one and $n-\pi^{*}$ transition of the N-oxide. It can be reduced into RF which has maximum absorption at $572 \mathrm{~nm}$ (Porcal et al. 2009). The photocatalysis experiment was carried out in glass reactors containing $10 \mathrm{~mL}$ of $\mathrm{RZ}$ aqueous solution at a concentration of $1.5 \mu \mathrm{g} / \mathrm{mL}$ in the presence of GO-coated cotton fabrics. The photocatalytic reaction is monitored by the color change from blue into pink followed by the absorption spectra measured at regular time intervals.

\section{Growth of bacterial strains}

In this study, the antibacterial activity of the GO-coated cotton fabrics was studied against one Gram-positive (Streptococcus iniae) and Gram-negative bacteria (Escherichia coli $\mathrm{DH} 5 \alpha$ ). E. coli $\mathrm{DH} 5 \alpha$ is obtained from the Department of Marine Life Sciences, Jeju National University, Republic of Korea. S. iniae was gifted by professor Sung-Ju Jung, Department of Aqualife Medicine, Chonnam National University, Republic of Korea. E. coli cells were grown on LB agar plates (lysogeny broth containing $1.5 \%$ agar), whereas $S$. iniae was grown in BHI medium supplemented with $1 \% \mathrm{NaCl}$ (BHIS) plates, respectively. Petri plates were incubated at species-specific temperatures $\left(37^{\circ} \mathrm{C}\right.$ : E. coli; $30^{\circ} \mathrm{C}$ : S. iniae) for $18-24 \mathrm{~h}$. Single colonies were inoculated into respective media $(5 \mathrm{~mL})$ and cultured overnight at species-specific temperatures. This culture was seeded in a final volume of $50 \mathrm{~mL}$ to further grow the bacteria. When optical density $\left(\mathrm{OD}_{600}\right)$ reached 0.6 , cells were harvested by centrifugation at $3,500 \mathrm{rpm}$ for $30 \mathrm{~min}$ at $4^{\circ} \mathrm{C}$. The harvested cells were washed twice with saline solution $(0.9 \% \mathrm{NaCl})$ to remove the residual media components and then resuspended with saline. Finally, the cells were spectrophotometrically (Bio-Rad, USA) quantified.

\section{Antibacterial property of GO-coated cotton fabrics}

The modified Hohenstein method was adopted to evaluate the antibacterial activity of GO-coated fabrics against both Gram-positive ( $S$. iniae) and Gram-negative (E. coli DH5 $\alpha)$ models (Vaideki et al. 2007). Bacterial strains were resuspended in saline solution with a final bacterial cell concentration of $\sim 10^{7}$ cells $/ \mathrm{mL}$. Cotton fabrics specimens were added into the tube and ensured it was fully immersed in inoculums. The mixture was then incubated in a shaking incubator at $200 \mathrm{rpm}$ at species-specific temperatures for 24 h. A blank was arranged for each strain without adding the coated fabrics specimen and just before taking the inoculums for plating, coated cotton fabrics were added in such a way to acquire the data at 'zero contact time'. The reduction in the bacterial concentration incubated with the specimens in different standard time intervals of 6, 12 and
$24 \mathrm{~h}$ was measured. The anti-bacterial potential of the GO particle-coated cotton fabrics was determined by comparing the reduction in viable bacterial population of the coated fabric specimen to that of control sample and expressed as a percentage reduction in standard time intervals. The inoculum was serially diluted up to $10^{4}$ cells/ $\mathrm{mL}$ and uniformly spread on respective media plates at different cell concentrations (with blanks). Plates were incubated for overnight at species-specific temperatures. The colony forming units (CFU) were counted from a series with optimum cell population. Evaluation was carried out on the basis of a modified method of Hohenstein test and the percentage reduction was calculated using the following formula (Vaideki et al. 2007):

$R=((B-A) / B)^{*} 100$

where $R$ is percentage reduction, $A$ is the number of bacteria recovered from the broth inoculated with GO-coated cotton fabric specimen and $B$ is the number of bacteria recovered from the broth inoculated with control fabrics (pure cotton fabrics) specimen after the desired contact period $(6,12$ and $24 \mathrm{~h})$ immediately after inoculation.

\section{Results and discussions}

\section{Characterization of graphene oxide nanostructures}

GO nanostructures are synthesized using harsh oxidation according to the modified Hummer's method. The characterization of GO nanostructures including the XRD, photoluminescence spectra, transmission electron microscope (TEM) is discussed in detail in our previous report (Karthikeyan et al. 2011). Figure 1a shows the UV-vis spectroscopy of GO nanostructures with maximum absorption peak at $227 \mathrm{~nm}$ which was attributed to the $\pi-\pi^{*}$ transitions of the aromatic $\mathrm{C}-\mathrm{C}$ bonds (Karthikeyan et al. 2011). The band gap energy calculated from the UVvis absorption spectra is $3.26 \mathrm{eV}$ which lies in the UV range. The presence of oxygenated functional groups in GO nanostructures is confirmed using FTIR spectroscopy as shown in Fig. 1b. The FTIR spectrum of GO illustrates the presence of $\mathrm{C}=\mathrm{O}\left(1,728 \mathrm{~cm}^{-1}\right), \mathrm{C}-\mathrm{OH}\left(1,413 \mathrm{~cm}^{-1}\right)$, C-O-C $\left(1,250 \mathrm{~cm}^{-1}\right)$, and C-O $\left(1,050 \mathrm{~cm}^{-1}\right)$ (Du et al. 2010). The peak at $1,600 \mathrm{~cm}^{-1}$ arises due to the $\mathrm{C}-\mathrm{C}$ vibrations from the graphitic domains ( $\mathrm{Si}$ and Samulski 2008). All these functional groups present in GO make them hydrophilic nature while the graphene and graphite are hydrophobic in nature. The surface morphology of GO nanostructures is studied using the SEM by placing a drop of GO dispersion into a glass substrate. The SEM image of GO nanostructure is shown in Fig. 2 representing the sheetlike morphology. It also resembles that some of the 

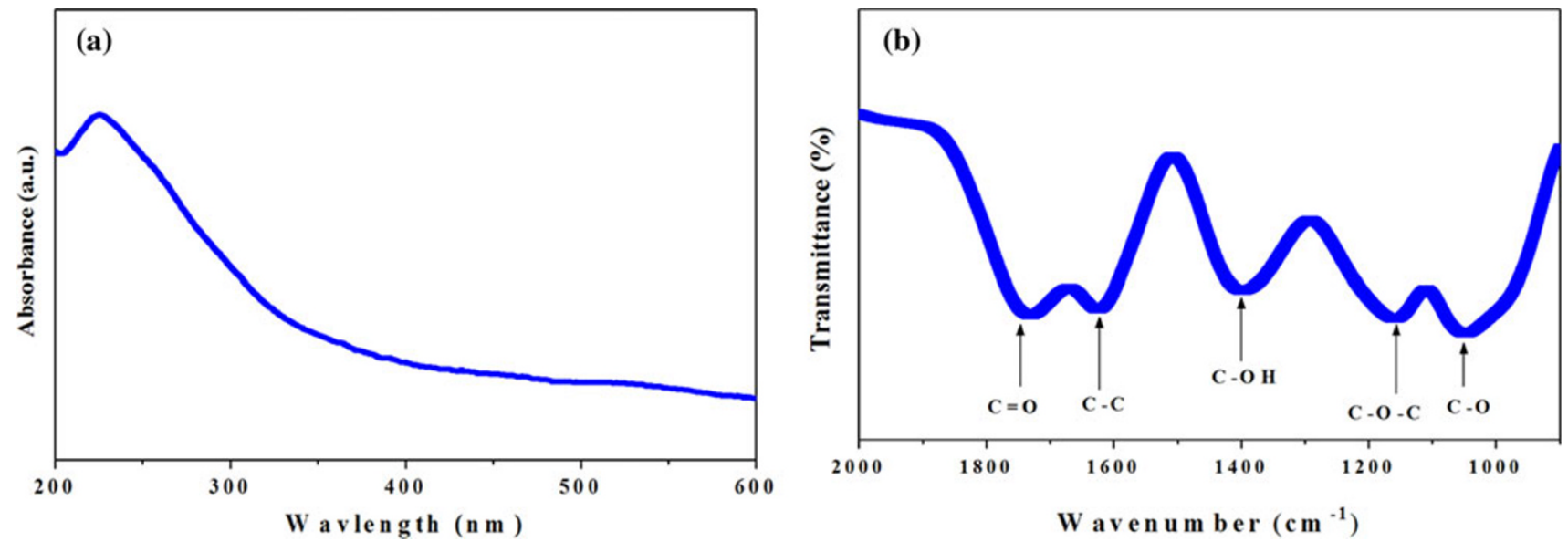

Fig. 1 a UV-vis spectrum of GO nanostructures and b FTIR spectra of GO nanostructures

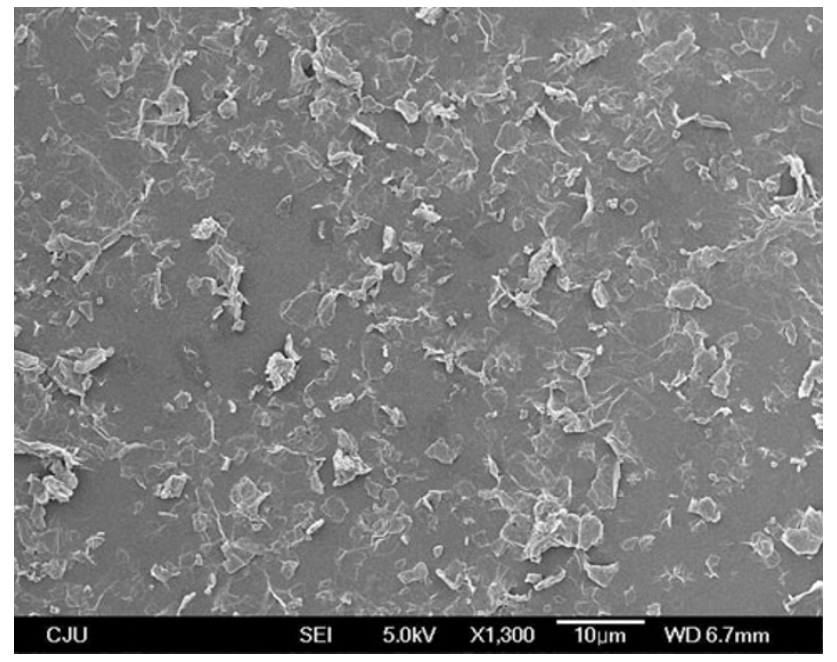

Fig. 2 SEM observations of GO nanostructure
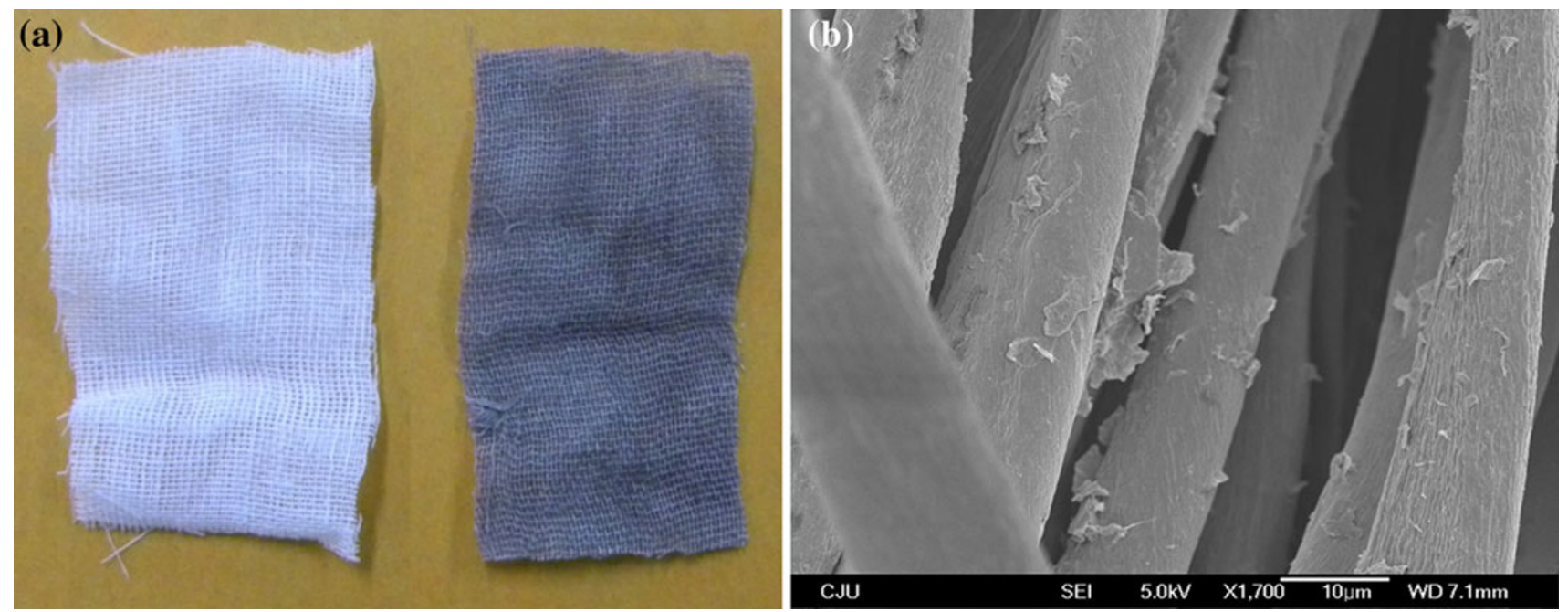

Fig. 3 a Photography of bare cotton fabric and GO-coated cotton fabric and b SEM observations of GO-coated cotton fabric particles look aggregated. The aggregation behavior in GO is usual due to the strong interaction between oxygenated functional groups in the multilayered GO .

\section{Characterization of GO-coated cotton fabrics}

The GO nanostructures are coated onto the cotton fabrics using dip coating process. GO is an attractive material with exceptional properties such as its high stability in aqueous solution, highly electronegative, molecular level dispersion in water etc., allows it to adhere on the surface cotton fabrics very rapidly. The amount of GO coated onto the fabrics is calculated as $0.025 \mathrm{~g}$ using the weight method using Eq. (1). The photographic image of GO-coated cotton fabrics is shown in Fig. 3a. The white color of the control fabric changed into blackish brown color after GO coating confirms that GO is uniformly coated on the 


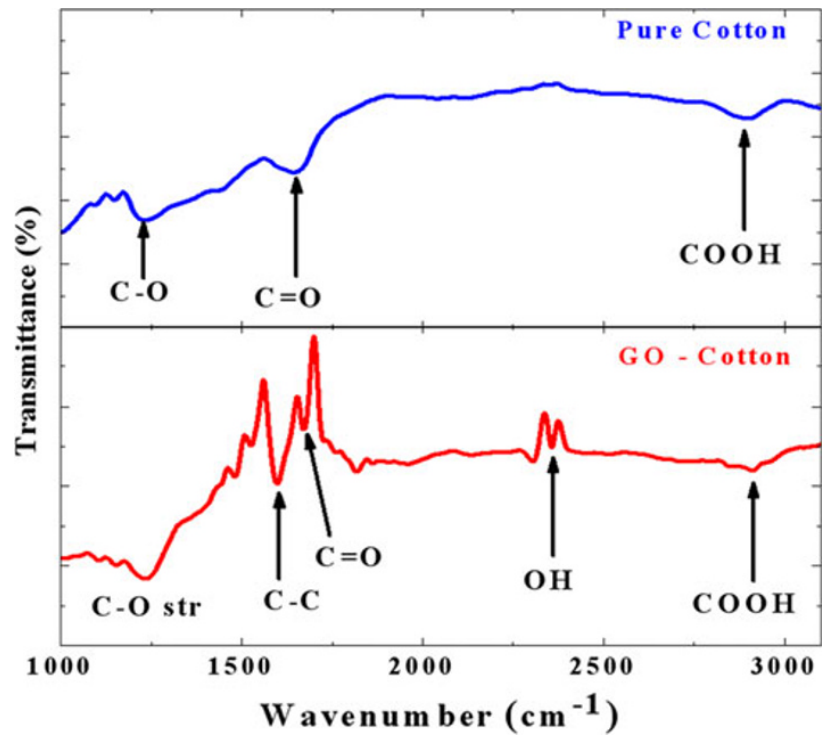

Fig. 4 FTIR spectra of pure cotton fabric and GO-coated cotton fabric

fabrics. Figure $3 \mathrm{~b}$ shows the scanning electron microscopic (SEM) image of the GO-coated cotton fabrics. It clearly reveals the presence of GO nanosheets coated on the surface of the cotton fabrics.

The mechanism of the adhesion of GO into the fabric is described as follows: GO has various functional groups such as carboxyl, carbonyl and hydroxyl, epoxyl groups make them hydrophilic nature (Karthikeyan et al. 2011; Si and Samulski 2008). The hydrophilicity of GO allows them to be readily soluble in water at molecular levels with high surface capacity for adsorption which results in adhering strongly onto the surface of cotton fabrics during the reaction time. This strong adhesion of GO into the surface of the fabric is confirmed from FTIR spectroscopy of control and GO-treated fabrics as shown in Fig. 4. The FTIR spectra of untreated fabrics exhibit the vibrational modes of $\mathrm{C}=\mathrm{O}$ stretching, $\mathrm{C}-\mathrm{O}$ stretching and $\mathrm{O}-\mathrm{H}$ deformation mode in the region of 1,200 to $1,700 \mathrm{~cm}^{-1}$ (Vaideki et al. 2007). The presence of the trace amount of HO-C $=\mathrm{O}$ shows peak in the $2,800 \mathrm{~cm}^{-1}$ region. The FTIR spectra of GO-coated fabric show significant changes compared to the free cotton fabric. The FTIR of GO-coated textile fabrics shows the presence of $\mathrm{C}-\mathrm{C}$ stretching mode at $1,600 \mathrm{~cm}^{-1}$ proves that the $\mathrm{GO}$ material is coated onto the fabrics. The usual carboxyl peak at $1,651 \mathrm{~cm}^{-1}$ in the cotton fabric is shifted towards the higher wavenumber at $1,671 \mathrm{~cm}^{-1}$ after GO is coated. And also the appearance of new peak at $2,300 \mathrm{~cm}^{-1}$ is due to the $\mathrm{O}-\mathrm{H}$ stretching modes of vibration which formed as a result of binding of $\mathrm{O}-\mathrm{H}$ group present in the GO with the cotton fabric. These changes occurred ensure that GO is coated onto the cotton fabrics successfully.

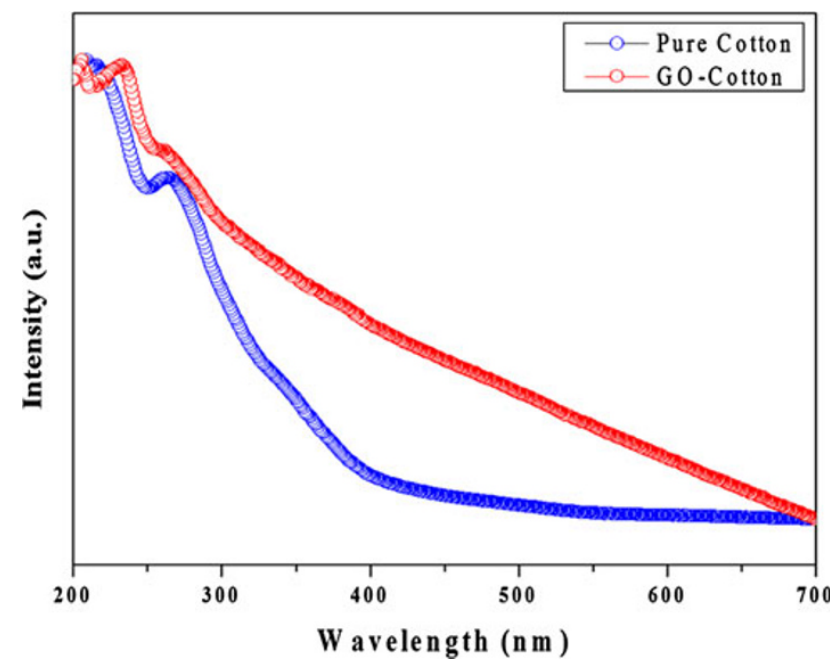

Fig. 5 UV-vis spectra of pure cotton fabric and GO-coated cotton fabric

The UV-vis spectrum of the pure cotton fabrics and the GO-coated cotton fabrics is shown in Fig. 5. As compared to the pure cotton fabrics, the absorbance of UV light $(200-400 \mathrm{~nm})$ is significantly increased in the spectrum of GO-coated cotton fabrics which is due to the good UV absorbance property of GO.

Multifunctional properties of GO-coated cotton fabrics

\section{Thermal stability of GO-coated cotton fabrics}

The thermal stability of the control fabric and the GOcoated fabric is examined using thermogravimetric analysis (TGA) and is shown in Fig. 6. TGA of control fabric exhibited a minor weight loss at $132.27^{\circ} \mathrm{C}$ is probably due to the removal of moisture content. The onset of melting peak arises gradually from $200^{\circ} \mathrm{C}$. After $250^{\circ} \mathrm{C}$, the major decomposition of the control peak starts and it reaches the peak melting point at $365.32^{\circ} \mathrm{C}$. In the TGA of GO-coated

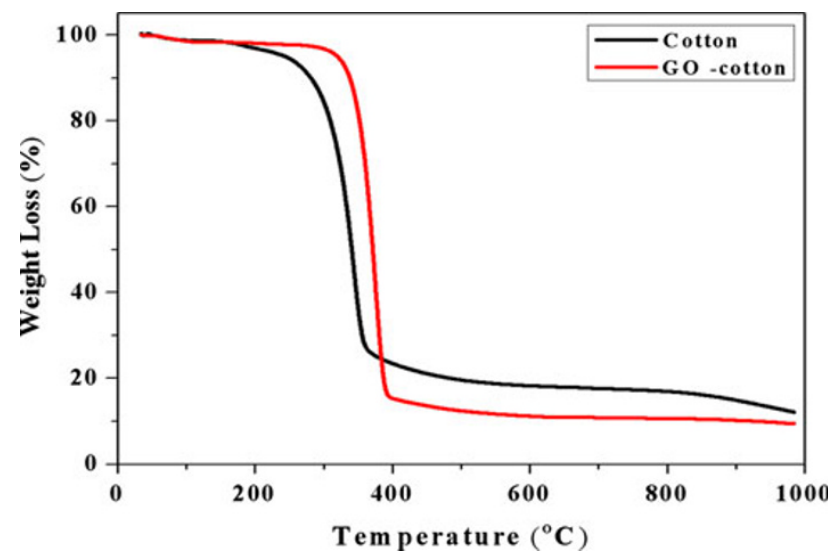

Fig. 6 TGA curve of bare cotton fabric and GO-coated cotton fabric

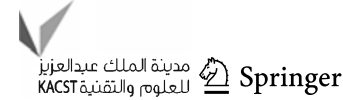


fabrics, the small transition at $153.45^{\circ} \mathrm{C}$ is due to the removal of moisture content. The onset of the melting peak arises at $330^{\circ} \mathrm{C}$ and the corresponding peak melting transition is observed at $391.55^{\circ} \mathrm{C}$. The transition of GO which usually occurs around $200^{\circ} \mathrm{C}$ is not observed in the TGA curve of GO-coated cotton fabrics due to the lower weight fraction of GO present in the cotton surface. The increase in the peak melting point is about $36^{\circ} \mathrm{C}$ signifies the strong molecular level interaction between the GO and the fabric which is obvious from the result of FTIR and also due to the $\mathrm{C}-\mathrm{C}$ skeleton in the $\mathrm{GO}$ nanostructures.

\section{Photocatalytic activity of GO-coated cotton fabrics}

The photocatalytic activity of GO nanostructures was discussed recently in our previous report (Karthikeyan et al. 2011). The photocatalytic activity of the prepared GOcotton fabrics was studied by the reduction experiments using RZ dye as a model compound. Figure 7 shows spectroscopic changes occurred during the photoreduction in RZ into RF in the presence of GO-coated cotton fabrics under UV irradiation at regular time intervals. It clearly shows that upon regular time intervals of UV irradiation, the intensity of the RZ (absorption peak at $600 \mathrm{~nm}$ ) decreased steadily. Simultaneously, another peak at $572 \mathrm{~nm}$ starts arising after UV exposure which corresponds to the formation of RF by the reduction of RZ catalyzed by GO-coated cotton fabrics. In the control experiments, there is no reduction in RZ that takes place in the conditions, viz., (a) RZ without any fabric in the presence of UV irradiation (b) RZ with bare-coated fabrics in the presence of visible light and (c) RZ with GO-coated fabrics in the presence of visible light. These observations confirmed that the reduction of RZ into RF occurs only in the presence of GO-coated cotton fabrics under UV irradiation.

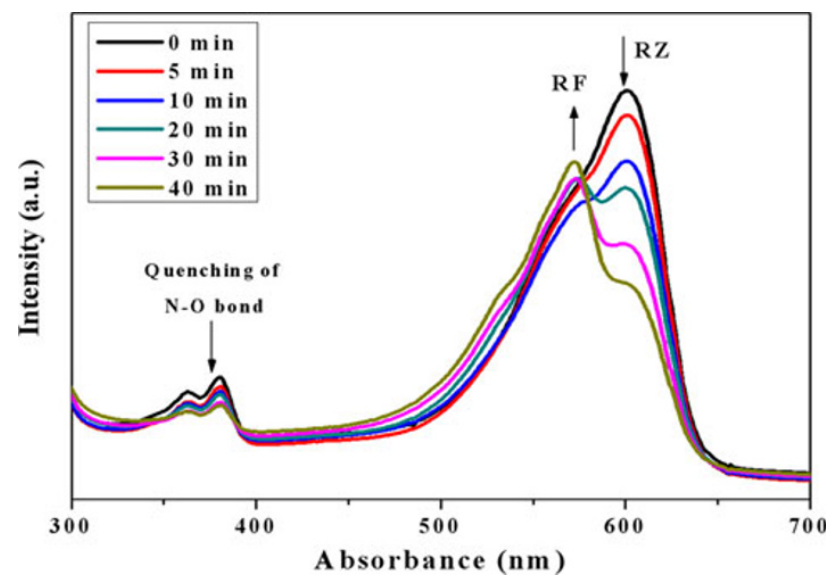

Fig. 7 Photocatalytic activity of GO-coated cotton fabric showing the time-dependent photoreduction of RZ into RF by the quenching of $\mathrm{N}-\mathrm{O}$ bond in $\mathrm{RZ}$ under UV irradiation
The reduction of $\mathrm{RZ}$ into $\mathrm{RF}$ in the presence of $\mathrm{UV}$ irradiation catalyzed by GO-coated cotton fabrics can be explained as follows: When UV- light of energy $(3.54 \mathrm{eV})$ which is significantly greater than the energy gap of GO ( $3.26 \mathrm{eV}$ as seen in $\mathrm{UV}$ spectra of $\mathrm{GO}$ ) is irradiated on the GO-coated cotton fabrics, electrons and hole pairs will be produced on the surface of GO. This photoexcited electron generated from the GO-cotton surface reduces the RZ molecule (blue) into RF molecule (pink) by destabilizing the $\mathrm{N}-\mathrm{O}$ bond in the RZ molecule. This is supported well with the time-dependent UV-vis spectra shown in Fig. 7 showing the quenching of peak at $380 \mathrm{~nm}$ with increase in time.

\section{Antibacterial activity of GO-coated cotton fabrics}

The antibacterial activity of GO-coated cotton fabric was examined against Gram-negative bacteria (E. coli $\mathrm{DH} 5 \alpha)$ and Gram-positive bacteria (S. iniae) and results are shown in Fig. 8. The quantitative bacterial reduction test was performed using modified Hohenstein method for the antibacterial efficacy of the GO modified cotton fabrics (Vaideki et al. 2007).

The experimental results revealed the time-dependent reduction of bacterial growth when exposed to GO-coated fabrics. The percentage reduction of Gram-negative bacteria and Gram-positive bacteria after $6,12,24 \mathrm{~h}$ exposure with GO-coated cotton fabrics is $46,62,74 \%$ and 68,86 , $100 \%$, respectively. It shows that GO-coated cotton fabrics are more effective towards the Gram-positive bacteria than the Gram-negative bacteria. Since the GO-coated fabric is more sensitive towards Gram-positive bacteria, to verify the nature of its toxicity towards bacterial species we also examined the antibacterial activity of GO nanostructures towards the same species and found that the GO is more toxic to Gram-positive ones. This is in agreement with the previous studies on the antibacterial activity of GO nanostructures (Akhavan and Ghaderi 2010). The differential toxicity of the GO-coated cotton fabrics may be due to

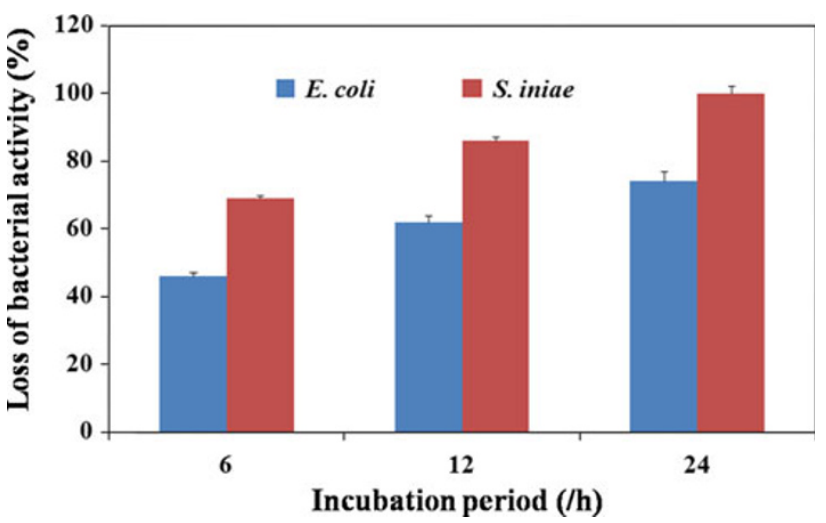

Fig. 8 Antibacterial activity of GO-coated cotton fabric towards $E$. coli and S. iniae 
many factors such as the primary difference between the Gram-negative and Gram-positive bacteria with respect to the nature of their cell wall (Applerot et al. 2011). In addition to this, the Gram-negative bacteria possess an additional outer membrane comprising of lipopolysaccharide which protects the peptidoglycan layer from chemical attacks (Eaton et al. 2008).

The antibacterial mechanism of the GO-coated cotton fabrics may be either due to the direct contact mechanism or oxidative stress which have been observed in the cytotoxic effects of carbon nanomaterials such as CNTs, graphene oxide, graphene, etc., (Manna et al. 2005; Liao et al. 2011). The former is due to the chemical composition of GO which contains several oxygenated functional groups such as carbonyl, carboxyl and epoxyl groups on their surfaces which makes them negatively charged, and easily bind to the bacterial cell walls and damage them. The latter is due to the reactive oxygen species produced by GO which can also contributes to the antibacterial activity of the GO-coated cotton fabrics.

\section{Conclusions}

In summary, GO nanostructures were successfully coated onto the cotton fabrics using a facile method. SEM observations reveals the presence of GO in the surface of the cotton fabrics. The FTIR analysis confirmed the molecular level interaction between the cotton fabrics and GO nanostructures. The results of TGA analysis showed that GO-coated cotton fabrics possess enhanced thermal stability compared to the bare cotton fabrics. Moreover, the GO-coated cotton fabrics showed photocatalytic activity by the reduction of RZ into RF under UV irradiation. The antibacterial activity of the GO-coated fabric shows better toxicity towards Gram-positive bacteria than the Gramnegative ones. Hence our efforts in this research level may find more practical applications of developing graphene oxide based antimicrobial coating for improving human health care.

\begin{abstract}
Acknowledgments This research was supported by National Research Foundation of Korea Grant under Contract Nos. 2009-0087091 and 2011-0015829, through the Human Resource Training Project for Regional Innovation. A part of this work was carried out at the Research Instrument Center (RIC), Jeju National University, Jeju, Republic of Korea.
\end{abstract}

Conflict of interest There is no conflict of interest.

Open Access This article is distributed under the terms of the Creative Commons Attribution License which permits any use, distribution and reproduction in any medium, provided the original author(s) and source are credited.

\section{References}

Akhavan O, Ghaderi E (2010) Toxicity of graphene and graphene oxide nanowalls against bacteria. ACS Nano 4:5731-5736

Applerot G, Lipovsky A, Dror R, Perkas N, Nitzan Y, Lubart R et al (2011) Enhanced antibacterial activity of nanocrystalline $\mathrm{ZnO}$ due to increased ROS-mediated cell injury. Adv Funct Mater 19:842-852

Dastjerdi R, Montazer M (2010) A review on the application of inorganic nano-structured materials in the modification of textiles: focus on anti-microbial properties. Colloids Surf B 79:5-18

Du Q, Zheng M, Zhang L, Wang Y, Chen J, Xue L, Dai W, Ji G, Cao J (2010) Preparation of functionalized graphene sheets by a low-temperature thermal exfoliation approach and their electrochemical supercapacitive behaviors. Electrochim Acta 55:3897-3903

Eaton P, Fernandes JC, Pereira E, Pintado ME, Malcata FX (2008) Atomic force microscopy study of the antibacterial effects of chitosans on Escherichia coli and Staphylococcus aureus. Ultramicroscopy 108:1128-1134

French GL (2005) Clinical impact and relevance of antibiotic resistance. Adv Drug Deliv Rev 57:1514-1527

Fu G, Vary P, Lin CT (2005) Anatase TiO2 nanocomposites for antimicrobial coatings. J Phys Chem B 109:8889-8898

Hegemann D, Hossain MM, Balazs DJ (2007) Nanostructured plasma coatings to obtain multifunctional textile surfaces. Prog Org Coat $58: 237-240$

Hu W, Peng C, Luo W, Lv M, Li X, Li D, Huang Q, Fan C (2010) Graphene-based antibacterial paper. ACS Nano 4:4317-4323

Joung D, Chunder A, Zhai L, Khondaker SI (2010) Space charge limited conduction with exponential trap distribution in reduced graphene oxide sheets. Appl Phys Lett 97:093105$1-093105-3$

Karthikeyan K, Poornaprakash N, Selvakumar N, Jeyasubrmanian K (2009) Thermal properties and morphology of MgO-PVA nanocomposite film. JNPN 5:83-88

Karthikeyan K, Mohan R, Kim S.-J (2011) Graphene oxide as a photocatalytic material. Appl Phys Lett 98:244101-1-244101-3

Kumar A, Vemula PK, Ajayan PM, John G (2008) Silvernanoparticle-embedded antimicrobial paints based on vegetable oil. Nat Mater 7:236-242

Liao KH, Lin YS, Macosko CW, Haynes CL (2011) Cytotoxicity of graphene oxide and graphene in human erythrocytes and skin fibroblasts. ACS Appl Mater Interfaces 3:2607-2615

Mahltig B, Audenaert F, Böttcher H (2005) Hydrophobic silica sol coatings on textiles-the influence of solvent and sol concentration. J Sol Gel Sci Tech 34:103-109

Manna SK, Sarkar S, Barr J, Wise K, Barrera EV, Jejelowo O, Rice-Ficht AC, Ramesh GT (2005) Single-walled carbon nanotube induces oxidative stress and activates nuclear transcription factor-B in human keratinocytes. Nano Lett 5: $1676-1684$

Porcal GV, Previtali CM, Bertolotti SG (2009) Photophysics of the phenoxazine dyes resazurin and resorufin in direct and reverse micelles. Dyes Pigments 80:206-211

Premanathan M, Karthikeyan K, Jeyasubramanian K, Manivannan G (2011) Selective toxicity of $\mathrm{ZnO}$ nanoparticles toward Grampositive bacteria and cancer cells by apoptosis through lipid peroxidation. Nanomedicine NBM 7:184-192

Reddy KM, Feris K, Bell J, Wingett DG, Hanley C, Punnoose A (2007) Selective toxicity of zinc oxide nanoparticles to prokaryotic and eukaryotic systems. Appl Phys Lett 90:213902$1-213902-3$ 
Shukla S, Saxena S (2011) Spectroscopic investigation of confinement effects on optical properties of graphene oxide. Appl Phys Lett 98:073104-1-073104-3

Si Y, Samulski ET (2008) Synthesis of water soluble graphene. Nano Lett 8:1679-1682

Sreeprasad TS, Maliyekkal MS, Deepti K, Chaudhari K, Xavier PL, Pradeep T (2011) Transparent, luminescent, antibacterial and patternable film forming composites of graphene oxide/reduced graphene oxide. ACS Appl Mater Interfaces 3:2643-2654
Tsai TM, Chang HH, Chang KC, Liu YL, Tseng CC (2010) Comparative study of the bactericidal effect of photocatalytic oxidation by $\mathrm{TiO}_{2}$ on antibiotic-resistant and antibiotic-sensitive bacteria. J Chem Technol Biotechnol 85:1642-1653

Vaideki K, Jayakumar S, Thilagavathi G, Rajendran R (2007) A study on the antimicrobial efficacy of RF oxygen plasma and neem extract treated cotton fabrics. Appl Surf Sci 253:7323-7329

Vigo T (1981) Antibacterial fiber treatment and disinfection. Text Res J 51:454-465 